\title{
Cloning, Expression, and Purification of the Nucleocapsid Protein of SARS Coronavirus
}

\author{
N. A. Netesova, P. A. Belavin, E. V. Seregina, G. M. Ignat'ev, and Academician L. S. Sandakhchiev
}

Received January 12, 2004

An outbreak of severe acute respiratory syndrome (SARS) was for the first time described in the Guangdong province (China); then, this disease expanded to some other countries [1]. As early as in April 2003, close cooperation of researchers from many laboratories worldwide enabled the WHO to announce that the etiological agent of the disease was a new pathogen, SARS-coronavirus (SARS-CoV). Although SARS$\mathrm{CoV}$ belongs to the family of coronaviruses, it is related to none of the strains of the family described so far [2].

A purified preparation of the recombinant nucleocapsid protein of the SARS-CoV strain Frankfurt was for the first time obtained in this work. The yield of the protein was $80 \mathrm{mg}$ per liter of culture. This protein can be used as an antigen for detecting antibodies to SARSCoV. In addition, recombinant protein can be used in further structural and functional studies of SARS virus and construction of molecular model for screening antiSARS drugs.

According to the literature, the size of the SARS pathogen genome ranges from 29.797 to 29.751 bp [3, 4]. Analysis of complete genomes of coronaviruses failed to reveal the genome closest to SARS-CoV. The greatest degree of homology was found between SARS-CoV and type 2 bovine coronavirus [3-5].

The functions of viral proteins should be studied to provide a deeper insight into the mechanisms of SARS infection itself, improve diagnostic tests, and rapidly develop specific methods of treatment and prophylaxis of this disease. Therefore, cloning, expression, and elucidation of the properties of the main structural proteins of the SARS virus are particularly important problems [6-8].

Open-frame analysis of SARS genome translation based on comparison with structures of other coronaviruses described in the literature showed that several proteins encoded by the viral genome may play an important role associated with SARS pathology. These are replicases 1a and 1c, spike protein (S), matrix protein $\mathrm{M}$, nucleocapsid protein $\mathrm{N}$, and envelope protein $\mathrm{E}$ [9].

State Research Center for Virology and Biotechnology Vektor, pos. Kol'tsovo, Novosibirsk oblast, 630559 Russia
According to the published data, the nucleocapsid protein $\mathrm{N}$, an important structural protein, can be used as an antigen for detecting antibodies to coronaviruses $[10,11]$.

Although the extent of homology of the amino acid sequence of the SARS-CoV nucleocapsid protein $\mathrm{N}$ with other coronaviruses is $22-30 \%$, a short sequence enriched with lysine residues (KTFPPTEPKKDKKKKTDEAQ) is unique to the SARS virus [9]. Prob-

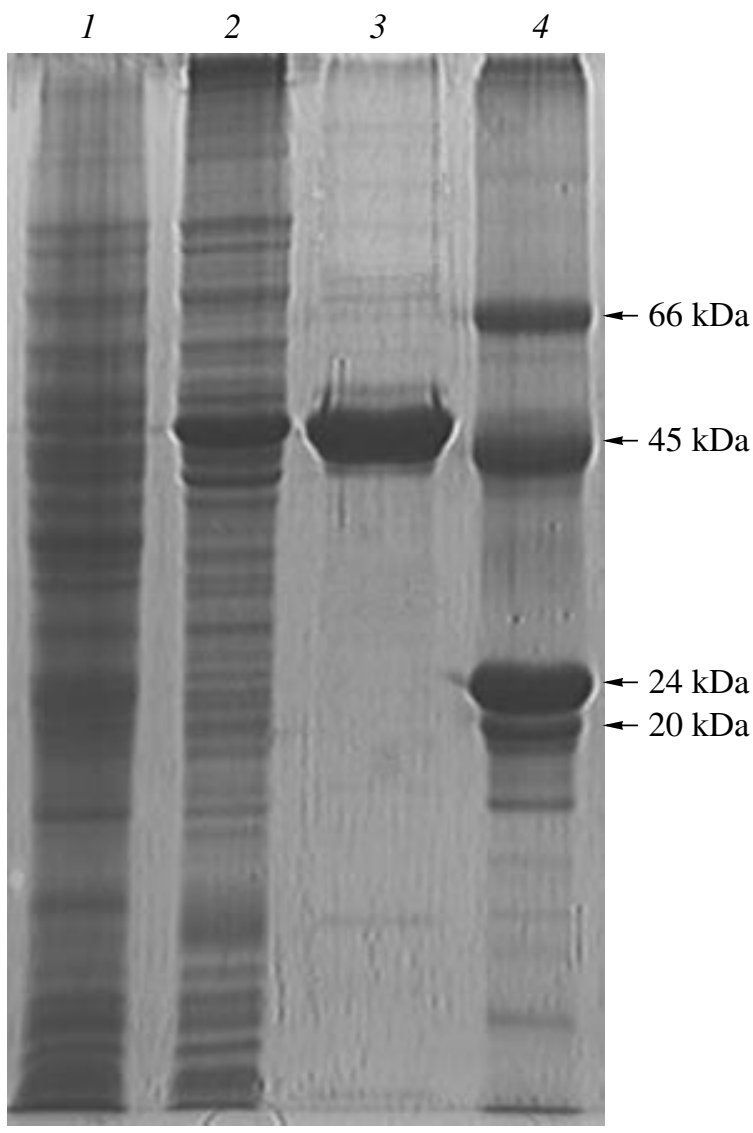

Fig. 1. Production of protein $\mathrm{N}$ of virus SARS in $E$. coli cells. Designation of lanes: (1) E. coli cells before induction, (2) E. coli cells after induction, (3) protein $\mathrm{N}$ after purification on Ni-NTA agarose; (4) molecular-weight markers. 
ably, nucleocapsid protein $\mathrm{N}$ is located in the nucleus and plays a key role in the SARS pathogenesis. In addition, nucleocapsid protein $\mathrm{N}$ is thought to be involved in RNA binding [9].

The SARS-CoV strain Frankfurt, used in this work, was kindly provided to the State Research Center for Virology and Biotechnology Vektor by Dr. H.W. Doerr (Frankfurt Institute of Medical Virology, Germany). The virus was obtained using the cell culture Vero, as described in [12].

Blood sera of patients with SARS, whose diagnosis was confirmed by laboratory analysis, were presented through the courtesy of Dr. H.W. Doerr (Frankfurt Institute of Medical Virology, Germany), Dr. W. Bellini (CDC, Atlanta, United States), and Dr. Wuchun Cao (Institute of Microbiology and Epidemiology, Beijing, People's Republic of China). Human blood serum containing no antibodies to coronavirus, presented by Dr. Wuchun Cao (Institute of Microbiology and Epidemiology, Beijing, People's Republic of China), was used as a negative control.

The E. coli strain BL21 (DE3), containing the RNA polymerase gene of phage T7, and E. coli strain XL-1 blue, used in this study, were from Promega (the United
States); restriction endonucleases, DNA ligase, Ttepolymerase, and desoxyribonucleotide phosphates were from Sibenzyme (Novosibirsk, Russia). Total DNA preparation was isolated and reverse transcription reaction was carried out using an RNeasy Mini kit (QIAGEN, Germany). Recombinant protein was purified on Ni-NTA agarose in accordance with the recommendations of the manufacturer (QIAGEN, Germany).

Additional nucleotides encoding the histidine tag were inserted in the upper primer of the expression plasmid pGSDI [13] during cloning of the protein $\mathrm{N}$ to provide gene amplification. The presence of this tag allows the recombinant protein to be purified by affinity chromatography on Ni-NTA agarose.

In addition, for the sake of convenience of manipulation using genetic engineering, additional sites of recognition of restriction endonucleases BglII and SalI were inserted in the primers used in the polymerase chain reaction.

The gene encoding the nucleocapsid protein $\mathrm{N}$ of SARS virus (length, 1327 bp) was obtained in the polymerase chain reaction using synthetic oligonucleotides of the following composition:

upper (N1)

$\begin{array}{cccc} & \text { BamHI } & \text { Start + His6-tag } & \text { BglII } \\ \text { 5'-CCC } & \text { GGATCC } & \text { ATGGCTAGCCATCACCATCACCATCAC } & \text { AGATCT }\end{array}$
ATGTCTGATAATGGACCCCAAT-3';

lower (N2)

\author{
SalI \\ 5'-CCC GTCGAC TGAGTGTTTATGCCTGAGTTGAA-3'.
}

The product of polymerase chain reaction was treated with the restriction endonucleases BamHI and SalI and ligated using the pGSD plasmid [13] pretreated with the restriction endonucleases BglII and SalI. E. coli strain XL-1 blue was transformed with a mixture of ligases.

Recombinant clones containing the target plasmid were selected by the method of polymerase chain reaction using the specific primers N1 and N2. The selected clones were tested by restriction analysis. As a result, the recombinant plasmid pHis-N was obtained. This plasmid contained the gene of the nucleocapsid protein $\mathrm{N}$ of the SARS virus strain Frankfurt. The pHis-N plasmid was used to transform the E. coli strain BL21 (DE3). Protein synthesis was induced by incubation with isopropyl- $\beta$ - $D$-thiogalactopyranoside (final concentration, $1 \mathrm{mM}$ ) for $5 \mathrm{~h}$.

Harvested cells were concentrated by centrifugation and sonicated using an ultrasonic disintegrator, and soluble fraction was purified on Ni-NTA agarose. Proteins were then electrophorezed under denaturing conditions [14].
The molecular weight of the protein synthesized in E. coli cells $(46 \mathrm{kD})$ coincided with the expected value (Fig. 1). The amount of recombinant protein, measured by densitometry of gel bands, was no less than $15 \%$ of total cell protein. The yield of the target protein was $80 \mathrm{mg}$ per liter of culture.

At the next stage of this work, we studied the interaction of the recombinant protein with serum by the method of enzyme-linked immunosorbent assay [15] using conjugated goat anti-human $\operatorname{IgG}(\mathrm{H}+\mathrm{L})$ HRP (ICN Biomedicals).

The results are shown in Fig. 2. It follows from Fig. 2 that the recombinant protein interacted with blood serum of patients with confirmed diagnosis of SARS (days 18, 21, and 35 of disease) and did not interact with negative serum.

Thus, in this work we obtained a purified preparation of the recombinant nucleocapsid protein of the SARS-CoV strain Frankfurt. The yield of the target protein was $80 \mathrm{mg}$ per liter of culture. This protein can be used as an antigen for detecting antibodies to SARS- 


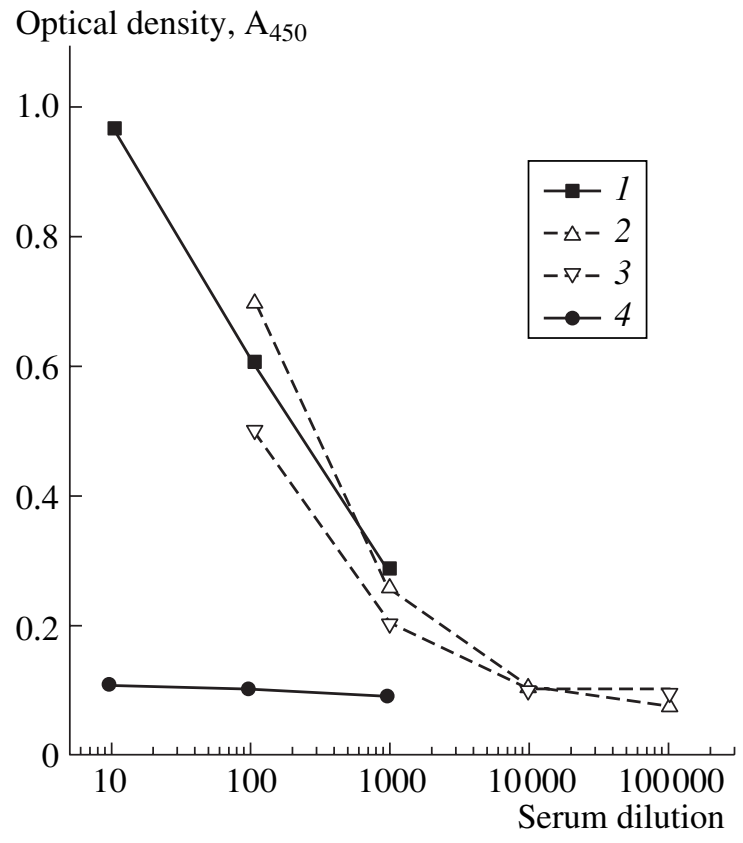

Fig. 2. Interaction of the recombinant protein with serum in the enzyme-linked immunosorbent assay (protein content, $1 \mu \mathrm{g}$ per well): (1) serum of patient on day 35 of the disease (Beijing, People's Republic of China, Dr. Wuchun Cao); (2) serum of patient on day 21 of the disease (CDC, United States, Dr. Bellini); (3) serum of patient on day 18 of the disease (Frankfurt, Germany, Dr. W.H. Doerr); (4) negative serum (Beijing, People's Republic of China, Dr. Wuchun $\mathrm{CaO})$.

CoV. In addition, the recombinant protein can be used in further structural and functional studies of SARS virus and construction of a molecular model for screening anti-SARS drugs.

\section{REFERENCES}

1. Morbid. Mortal. Weekly Rep., 2003, vol. 52, p. 550.

2. Rota, P., Oberste, S., Monroe, S., et al., Science, 2003, vol. 300, no. 5624, pp. 1394-1399.

3. Marra, M.A., Jones, S.J., Astell, C.R., et al., Science, 2003, vol. 300, no. 5624, pp. 1399-1404.

4. SARS-Coronavirus, Complete Genome, Entrez, NC_004718.

5. Lai, M.M.C. and Holmes, K.V., in Fields Virology, New York: Lippicott, Williams and Wilkins, 2001.

6. Shen, X., Xue, J.-H., Yu, C.-Y., et al., Acta Pharmacol. Sin., 2003, vol. 24, no. 6, pp. 505-511.

7. Zhang, X.L., Wang, J.R., Zhang, Y., et al., Acta Biochim. Biophys. Sin., 2003, vol. 35, no. 12, pp. 1140-1144.

8. Yu, H., Yang, Y., Zhang, W., et al., Acta Biochim. Biophys. Sin., 2003, vol. 35, no. 8, pp. 774-778.

9. Snijder, E.J., Bredenbeek, P.J., Dobbe, J.C., et al., J. Mol. Biol., 2003, vol. 331, no. 5, pp. 991-1004.

10. Ndifuna, A., Waters, A.K., Zhou, M., and Collisson, E.W., J. Virol. Methods, 1998, vol. 70, no. 1, pp. 37-44.

11. Chen, H., Coote, B., Attree, S., and Hiscox, J.D., Avian Pathol., 2003, vol. 32, no. 5, pp. 519-526.

12. Agafonov, A.P., Gus'kov, A.A., Ternovoi, V.A., et al., Dokl. Akad. Nauk, 2003, vol. 394, no. 4, pp. 566-568.

13. Belavin, P.A., Netesova, N.A., Reshetnikov, S.S., Eroshkin, A.M., Loktev, V.B., and Malygin, E.G., Biotekhnologiya, 1997, no. 3, pp. 3-9.

14. Laemmly, W.K., Nature, 1970, vol. 227, pp. 680-685.

15. Egorov, A.M., Osipov, A.P., Dzantiev, B.B., et al., Teoriya i praktika immunofermentnogo analiza (The Theory and Practice of Immunoenzyme Analysis), Moscow: Vysshaya Shkola, 1991. 